\title{
Endoscopic Spine Surgery
}

\author{
Gun Choi, M.D., Ph.D., Chetan S Pophale, M.D., Bhupesh Patel, M.D., Priyank Uniyal, M.D. \\ Department of Spine Surgery, Wooridul Spine Hospital, Pohang, Korea
}

Surgical treatment of the degenerative disc disease has evolved from traditional open spine surgery to minimally invasive spine surgery including endoscopic spine surgery. Constant improvement in the imaging modality especially with introduction of the magnetic resonance imaging, it is possible to identify culprit degenerated disc segment and again with the discography it is possible to diagnose the pain generator and pathological degenerated disc very precisely and its treatment with minimally invasive approach. With improvements in the optics, high resolution camera, light source, high speed burr, irrigation pump etc, minimally invasive spine surgeries can be performed with various endoscopic techniques for lumbar, cervical and thoracic regions. Advantages of endoscopic spine surgeries are less tissue dissection and muscle trauma, reduced blood loss, less damage to the epidural blood supply and consequent epidural fibrosis and scarring, reduced hospital stay, early functional recovery and improvement in the quality of life \& better cosmesis. With precise indication, proper diagnosis and good training, the endoscopic spine surgery can give equally good result as open spine surgery. Initially, endoscopic technique was restricted to the lumbar region but now it also can be used for cervical and thoracic disc herniations. Previously endoscopy was used for disc herniations which were contained without migration but now days it is used for highly up and down migrated disc herniations as well. Use of endoscopic technique in lumbar region was restricted to disc herniations but gradually it is also used for spinal canal stenosis and endoscopic assisted fusion surgeries. Endoscopic spine surgery can play important role in the treatment of adolescent disc herniations especially for the persons who engage in the competitive sports and the athletes where less tissue trauma, cosmesis and early functional recovery is desirable. From simple chemonucleolysis to current day endoscopic procedures the history of minimally invasive spine surgery is interesting. Appropriate indications, clear imaging prior to surgery and preplanning are keys to successful outcome. In this article basic procedures of percutaneous endoscopic lumbar discectomy through transforaminal and interlaminar routes, percutaneous endoscopic cervical discectomy, percutaneous endoscopic posterior cervical foraminotomy and percutaneous endoscopic thoracic discectomy are discussed.

Key Words : Endoscopic spine surgery · Percutaneous endoscopic lumbar discectomy · Percutaneous endoscopic cervical discectomy . Percutaneous endoscopic posterior cervical foraminotomy · Percutaneous endoscopic thoracic discectomy.

\section{INTRODUCTION}

Surgical treatment of the degenerative disc disease has evolved from traditional open spine surgery to minimally invasive spine surgery including endoscopic spine surgery. Con- stant improvement in the imaging modality especially with introduction of the magnetic resonance imaging (MRI), it is possible to identify culprit degenerated disc segment and again with the discography it is possible to diagnose the pain generator and pathological degenerated disc very precisely and

- Received : March 15, 2017 •Revised : April 21, 2017 •Accepted : April 26, 2017

- Address for reprints : Chetan S Pophale, M.D.

Department of Spine Surgery, Wooridul Spine Hospital, 256 Posco-daero, Buk-gu, Pohang 37755, Korea

Tel : +82-54-240-6129, Fax : +82-54-240-6195, E-mail : chetupophale@gmail.com

This is an Open Access article distributed under the terms of the Creative Commons Attribution Non-Commercial License (http://creativecommons.org/licenses/by-nc/4.0) which permits unrestricted non-commercial use, distribution, and reproduction in any medium, provided the original work is properly cited. 
its treatment with minimally invasive approach. With improvements in the optics, high resolution camera, light source, high speed burr, irrigation pump etc, minimally invasive spine surgeries can be performed with various endoscopic techniques for lumbar, cervical and thoracic regions. Advantages of endoscopic spine surgeries are less tissue dissection and muscle trauma, reduced blood loss, less damage to the epidural blood supply and consequent epidural fibrosis and scarring, reduced hospital stay, early functional recovery and improvement in the quality of life \& better cosmesis. With precise indication, proper diagnosis and good training, the endoscopic spine surgery can give equally good result as open spine surgery.

Initially, endoscopic technique was restricted to the lumbar, cervical and thoracic disc herniations but gradually it can also be used for spinal canal stenosis and endoscopic assisted fusion surgeries.

Endoscopic spine surgery can play important role in the treatment of adolescent disc herniations especially for the persons who engage in the competitive sports and the athletes where less tissue trauma, cosmesis and early functional recovery is desirable.

\section{HISTORY OF ENDOSCOPIC SPINE SURGERY}

Minimally invasive spine surgery treatment started in true sense by Lymen Smith in 1963 by injecting chymopapain intradiscally called chemonucleolysis ${ }^{7)}$.

Encouraged by results of chemonucleolysis, Kambin in 1970 initiated a feasibility study of mechanical nuclear debulking by inserting Craig cannula via posterolateral approach.

In 1975 Hijikata et al. ${ }^{6}$ from Japan independently performed mechanical nucleotomy via posterolateral access to the centre of the disc and reported $64 \%$ success rate. Following Hijikata's experience Schreiber and Suezawa developed a series of cannulas that were telescoped one over the other and placed in the centre of the intervertebral disc via a posterolateral access. The larger cannulas with a 7 to 8 -mm internal diameter (ID) permitted the insertion of larger forceps and more rapid evacuation of nuclear tissue.

Friedman and Jacobson had started using far lateral approach for lumbar disc herniation by using 40 no. French chest tube through incision over iliac crest passed towards in- tervertebral disc after manual nucleotomy disc fragments was removed with forceps ${ }^{4}$. This approach was further propagated by Ruetten et al. ${ }^{19)}$.

In 1985, Onik et al. ${ }^{18)}$ promoted the concept of central nucleotomy via a mechanical tool called a nucleotome. The small calibre of the instruments and the simplicity of the procedure contributed to the popularity of the operative technique in the following years.

Introduction of Laser opened new frontier in the minimally invasive spine surgery. In $1990 \mathrm{Kambin}^{11)}$ started using laser to vaporise disc fragment but its wide arc of deflection and injury to neural structure restricted an adequate decompression.

Posterolateral access was initially used for vertebral biopsy, chemonucleolysis, and discography and automated nucleotomy but the dimensions of safe zone and landing of instruments were not clearly defined. It was Kambin who had studied extensively on cadaver and described the boundaries of safe working zone for posterolateral approach between exiting and traversing nerve roots. Kambin also illustrated radiographic positioning of needle in anteroposterior and lateral views. He defined Kambin's triangle, base formed by superior endplate of lower lumbar vertebra, roof formed by traversing root and thecal sac curtailed by facet joint and anterior border formed by exiting root. Triangle is loosely covered by adipose tissue and small superficial vein ${ }^{9,10,13)}$.

Merkovic and his resident Schwartz independently measured dimensions of working zone and safe point for needle insertion in anteropoaterior and lateral radiographic views in 12 cadavers for endoscopic spine surgery. It was stipulated that medial one third or mid pedicular positioning should be utilise for subligamentous or intracanalicular(foraminal) disc herniation ${ }^{17}$.

All previous minimally invasive access studies to the disc were blind. It was Kambin and Sampson who described purely endoscopic visualisation technique for non sequestrated disc herniation as extraforaminal approach, but this technique gradually evolved into translaminar access for discectomy ${ }^{14)}$. In 1996 Mathews who was developing fibre optic endoscope for Sofamor Danek started using transforaminal endoscopic discectomy through foramen ${ }^{16}$.

During 1990 many spine surgeons started doing minimally invasive spine surgery by magnification loupe or under microscope. Destandau and Kevin Foley independently developed tubular retractor system and endoscopy aided spine sur- 
gery through interlaminar approach although Kevin Foley published first but it was Destandau who developed first and started using his system ${ }^{3,20)}$. In 1991 Kambin and Sampson ${ }^{14)}$ developed cannula (10-23 mm ID) for interlaminar and transforaminal endoscopy.

In 1997, Anthony Yeung had designed YESS endoscope; manufactured by Richard Wolf Surgical Instrument Company and 510k FDA approved multi-channel fluid integrated working channel rigid endoscope after which the modern era of endoscopic disc surgery was introduced. Yeung's technique of ' inside out' was based on principle of identification and treatment of pain generators into the foramen and the disc, by freeing exiting and traversing roots, by fragmentectomy, visualisation and clearance of annular tear by ablation and irrigation. Further expansion of technique to address decompression of the lateral canal and the hidden zone of Mcnab by cutting the tip of Superior articular process by various cutting and articulated instrument was developed by Gore and Yeung ${ }^{5,21,22)}$.

Hoogland described "Outside in" approach for transforaminal endoscopic technique by cutting the facet and direct landing into the epidural space but this technique is blind, requires foraminoplasty to access fragment, which can cause bleeding and poor visualisation ${ }^{7)}$.

Choi et al. contributed to the modification of endoscopic technique by access to the far lateral disc herniation, transiliac and interlaminar approach for difficult L5-S1 level disc herniations, approach for up migrated and down migrated disc herniations, transpedicular approach for high grade down migrated disc herniation and endoscopic treatment for lumbar spinal canal stenosis ${ }^{1,15}$.

\section{ENDOSCOPIC LUMBAR SPINE SURGERY}

In endoscopic lumbar spine surgery two approaches are most popular, Transforaminal and Interlaminar endoscopy.

\section{Transforaminal endoscopic lumbar discectomy (TELD)}

In the TELD, discecetomy and decompression is performed through intervertebral foramen between exiting and traversing root so before going in depth of TELD we need to know anatomy of intervertebral foramen (IVF). IVF is bounded by two mobile joints, zygapophyseal joints posteriorly and intervertebral disc anteriorly, because of mobility of two joints dimension of IVF change dynamically with movement of spine and with age related degeneration. Roof and floor are formed by inferior and superior notch of respective vertebral pedicles, medial wall by thecal sac and lateral wall by a facial sheath and overlying psoas muscle. Content of IVF are spinal nerves (combined dorsal and ventral roots in root sheath with dorsal root ganglia), dural sheath and its watershed area as it continue with epineurium of spinal nerve, lymphatics, spinal branch of segmental artery, communicating veins between internal and external vertebral venous plexus, sinuvertebral nerves (two to four) and the fat surrounding these structures.

Crux of TELD is precise insertion of needle into the disc through safe triangle of Kambin's which lies between the exiting and the traversing root.

Boundaries of the Kambin's triangle are anterior or hypotenuse line : exiting nerve root; base or inferior boundary : superior endplate of inferior vertebra; and roof or medial border : thecal sac and traversing nerve root curtailed by the facet.

The Pedicle and respective disc space chosen as radiographic landmark during percutaneous procedures. The point of needle insertion in radiographic view divided into vertical lines at medial, mid and lateral pedicular lines and horizontal line draw parallel to end plates in anteroposterior view and posterior vertebral line in lateral view. The medial pedicular line and posterior vertebral line are commonly used reference point for most of the transforaminal procedures.

The dimension of working zone is also important to pass safest and largest working cannula into the foramen. Mirkovic et al. ${ }^{17)}$ evaluated dimension of working zone in 12 cadaveric specimens from L1 to $\mathrm{S} 1$ foramens. According to them 6.3 $\mathrm{mm}$ cannula is safer when placed at mid pedicular line and 7.5 $\mathrm{mm}$ is safer when placed at medial pedicular line in Anteroposterior radiographic view. Most of the working cannulas available in markets are around $7.5 \mathrm{~mm}$ in diameter.

Indications

- Positive Straight leg raising test

- Radiating pain with or without neurological deficits

- Leg pain is more severe then back pain

- Sufficient conservative (non-surgical) treatment of 8 weeks

- Radiological examination findings correlate with the clinical symptoms and signs 


\section{Contraindications}

- Extensive migrated disc and extensive calcification of disc

- At L5-S1 level (particularly in male patients, the patient with long iliac wings)

- More than one level (relative contraindication)

- Spinal canal and foraminal stenosis (relative contraindication)

- Spondylolisthesis

- Recurrent disc herniation (reoperation)

- Nerve root anomalies such as conjugate root

- Cauda equine syndrome

\section{Surgical approach}

- TELD is performed under local anaesthesia (1\% lidocaine) and conscious sedation with midazolam $(0.05 \mathrm{mg} / \mathrm{kg}, 30$ mintues before surgery) and fentanyl $(0.8 \mu \mathrm{g} / \mathrm{kg}, 10 \mathrm{mint}-$ ues before surgery) in prone or lateral position. Prone position is preferred by most of the surgeons due to better anatomical orientation.

- Skin Entry point for needle insertion is calculated based on pre-operative MRI and computed tomography (CT scan) by measuring distance from midline and needle trajectory aimed to target ruptured fragment without entering peritoneal sac and just to graze the facet.

- Skin entry point is infiltrated with $1 \%$ lidocaine then Needle is directed 10 degrees downwards to make 10 degree angle with upper and lower end plates respectively and advanced further till first bony resistance of facet is encountered in C-arm anteroposterior (AP) view, minor adjustment of trajectory can be done by bevel of needle, by keeping it up allows to go more superficially and vice-ver- sa. Now under lateral view of C-arm withdraw needle little bit, elevate it and insert into the foramen by grazing the facet.

- Most important point is safe and precise landing into the lower part of Kambin's triangle. Use 6 to $8 \mathrm{~mL}$ local anaesthesia into the foramen to make the procedure more comfortable. Site of annular puncture is medial pedicular line in AP view and posterior vertebral line in lateral view in lower lumbar spine as lamina is wider so chance of dural puncture is less and med pedicular line in upper lumbar levels as lamina is narrow so chances of dural puncture is higher. Now pierce the annulus. Haptic feedback is very important (feels like rubber stopper) (Fig. 1).

- Once needle reaches into the centre of the disc in AP view perform a discography by injecting the mixture of $2-3 \mathrm{~mL}$ radiopaque dye (Telebrix, Guerbert, France), indigo carmine (Carmine; Korean United Pharma, Seoul, Korea) and normal saline mixed in $2: 1: 2$ ratios. Dye helps to identify nuclear fragment during surgery (Fig. 2).

- Replace the needle with guide wire and obturator passed over guide wire till it pierce annulus (Fig. 3). Remove the guide wire and thread the working cannula over obturator with help of mallet \& tapper (Fig. 4). Remove the obturator and introduce the endoscope (Spine Doctors, Seoul, Korea) through the working cannula.

- During a procedure watch for any undue pain radiating to the limb which is indicative of compression over exiting root (traversing root protected by facet) and change the needle trajectory accordingly.

- After introduction of endoscope try to identify the struc-
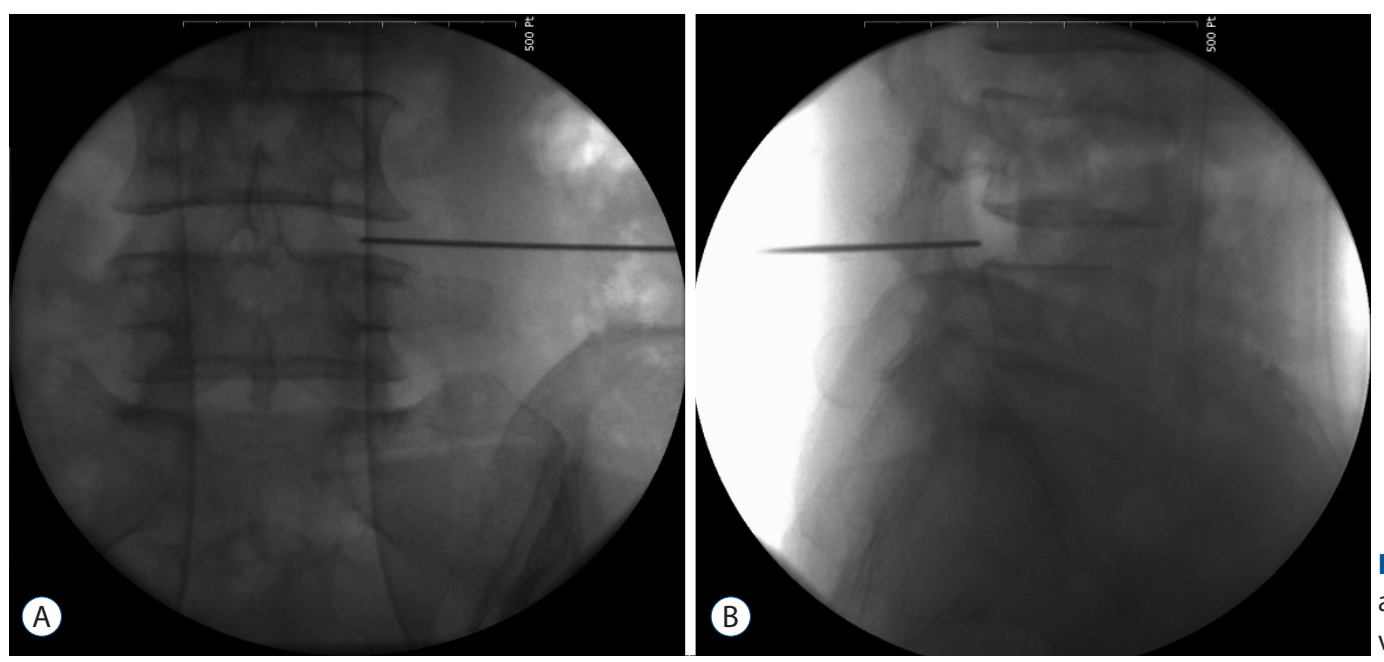

Fig. 1. Needle positioning (A) anteroposterior and (B) lateral view. 


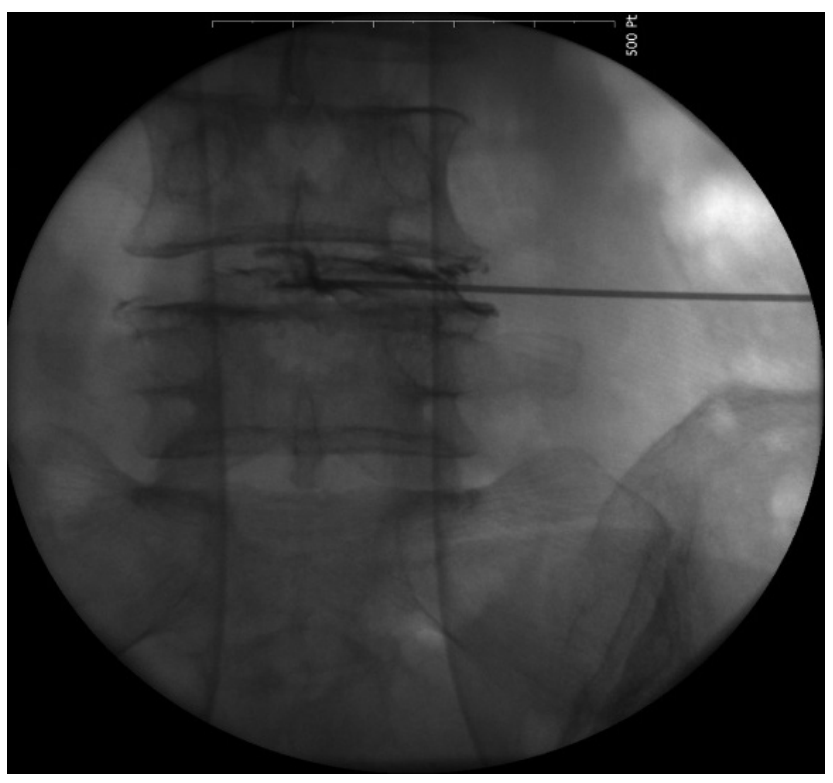

Fig. 2. Discography.

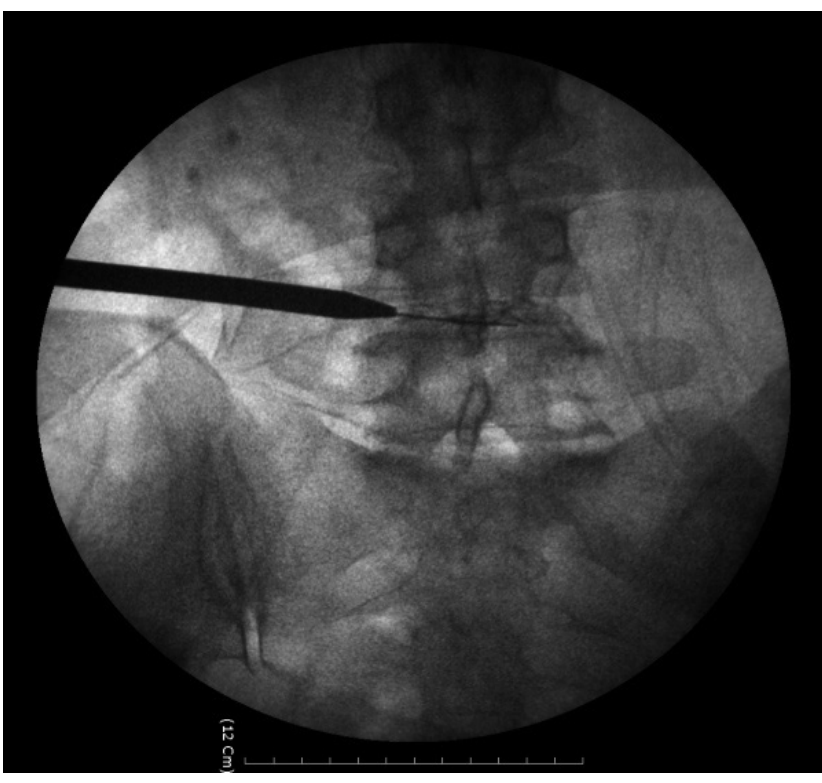

Fig. 3. Guide wire and obturator insertion.
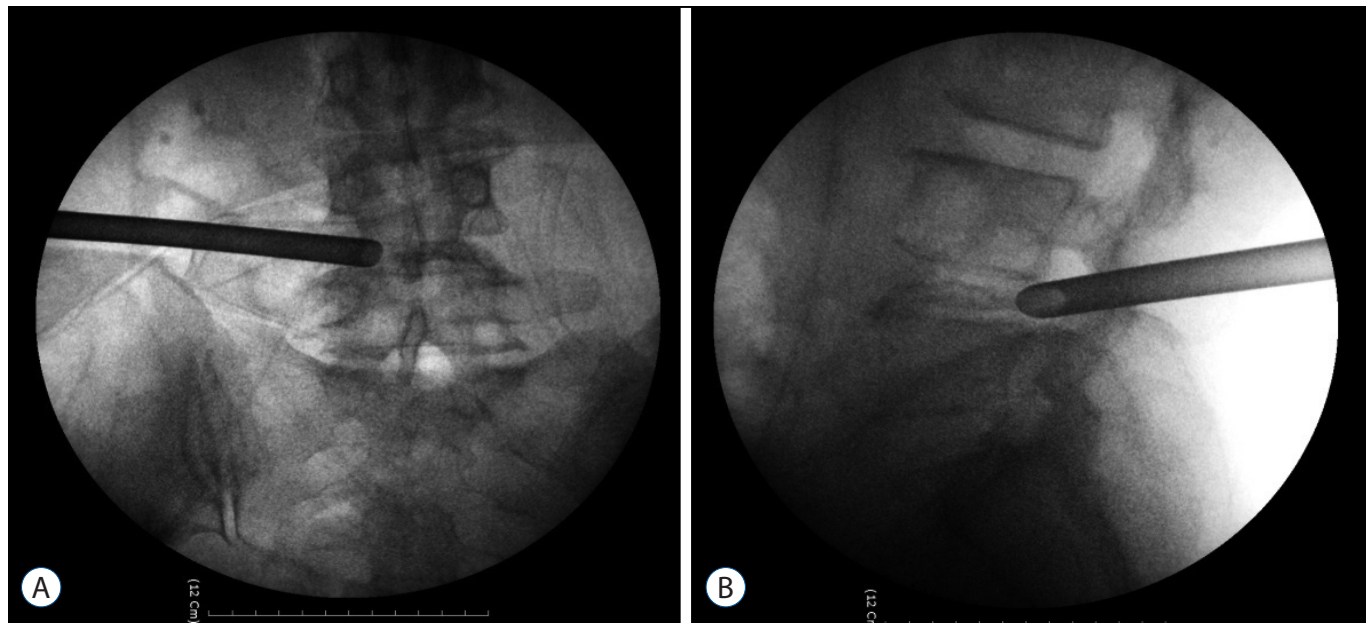

Fig. 4. Cannula positioning (A) anteroposterior and (B) lateral view.

tures like epidural fat, annular tear with nuclear caught fragment, posterior longitudinal ligament, traversing nerve root, exiting nerve root, superior facet and superior and inferior pedicular notches (Fig. 5). Remove the fragment with different types of forceps and clean the annular tear with bipolar cold coagulation (Elliquence, Baldwin, NY, USA) and Ho-YAG laser if needed.

- Free movement of thecal sac and traversing root, fresh epidural bleeding, and subsidence of pain are the signs of an adequate decompression.

- Pre-operative (Fig. 6) and post-operative MRI (Fig. 7) shows there is complete removal of herniated fragment.

Special modification of the standard technique is needed to tackle extra foraminal disc herniation and high grade up or down migrated disc herniations and high iliac crest for L5-S1 level.

For Extraforaminal disc herniation : 1) the needle trajectory needs to be steeper, 2) angle of insertion should be a 10 to $50 \%$ based on pre-operative images, 3) distance from midline should be a 5 to $8 \mathrm{~cm}, 4$ ) midpedicular line on AP and posterior vertebral line on lateral $\mathrm{C}$-arm view, and 5) direction of the needle should be superior end plate of caudal vertebra.

For Migrated disc herniation : 1) needle entry point should be lower to the disc space for up migrated disc herniation and vice-versa for down migrated disc herniation and 2) for high grade down migrated disc herniation, foraminoplasty (under- 


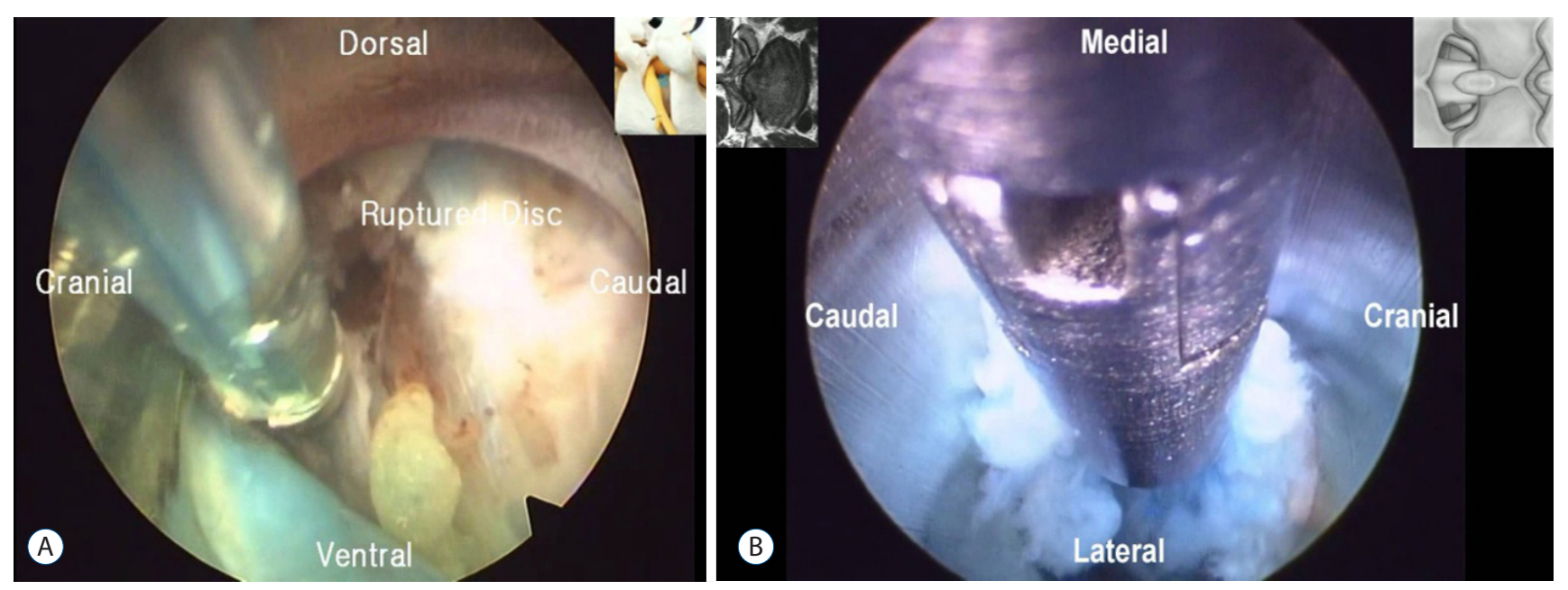

Fig. 5. (A and B) Endoscopic view.

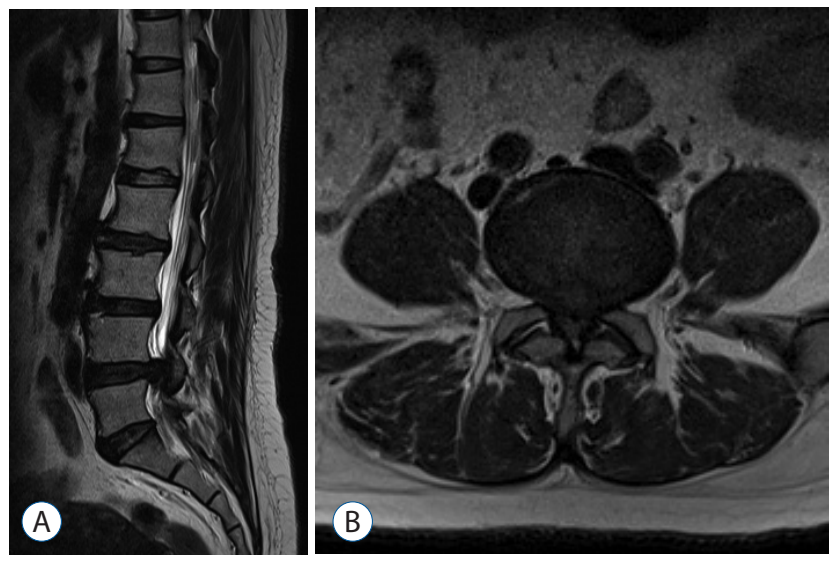

Fig. 6. Preoperative MRI. (A) Sagittal and (B) axial view. MRI : magnetic resonance imaging.

cutting the non articular part of the superior facet) or oblique pediculotomy (removal of superior and medial wall of the lower pedicle) may be needed.

\section{Interlaminar approach}

Transforaminal approach is sometimes difficult at L5-S1 level due to anatomical constrains like high iliac crest and upmigrated disc herniation where trajectory is not along the line of herniation. In such cases interlaminar approach can be useful.

Interlaminar window at $\mathrm{L} 5-\mathrm{S} 1$ is largest $(31 \mathrm{~mm})$ and little overhang of upper lamina makes interlaminar approach possible at L5-S1 level disc herniation. Two types of disc herniation axillary or shoulder type should be determined on preoperative images.

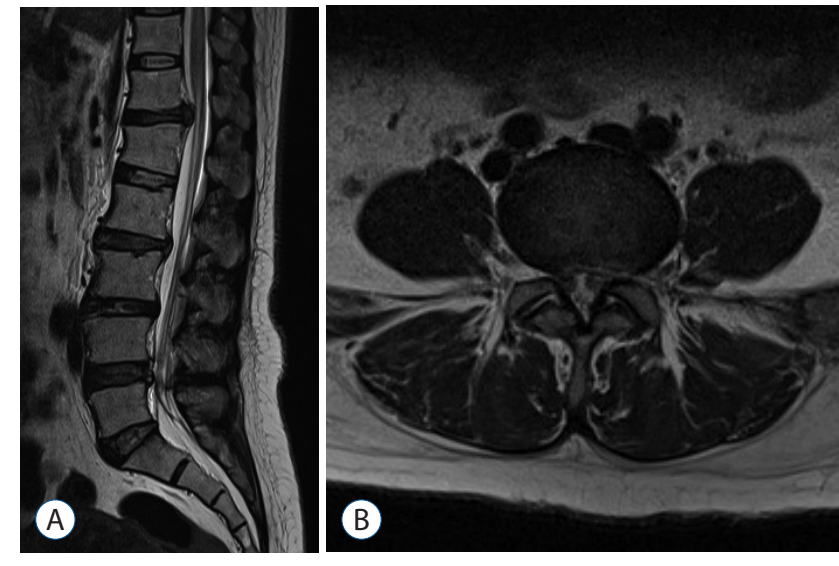

Fig. 7. Post-operative MRI. (A) Sagittal view and (B) axial view. MRI : magnetic resonance imaging.

\section{Surgical steps}

- Once location of disc herniation is determined on images needle entry point is to be calculated from images. Entry point should be in reference to the medial pedicular line in AP and spino-laminar line on lateral view with direction of needle towards superior endplate of S1 vertebra (Fig. 8). For shoulder herniation needle to be directed at superomedial aspect of pedicle and axillary herniation it should be directed towards lower lamina (midpoint of pedicle and spinous process).

- Once needle reaches to spinolaminar junction, the needle tract is dilated with series of dilators and endoscope (Spine Doctors) to be introduced. First structure encountered is ligamentum flavum which when splitted, epidural fat is seen (Fig. 9). Bipolar radiofrequency coagulation is used to 


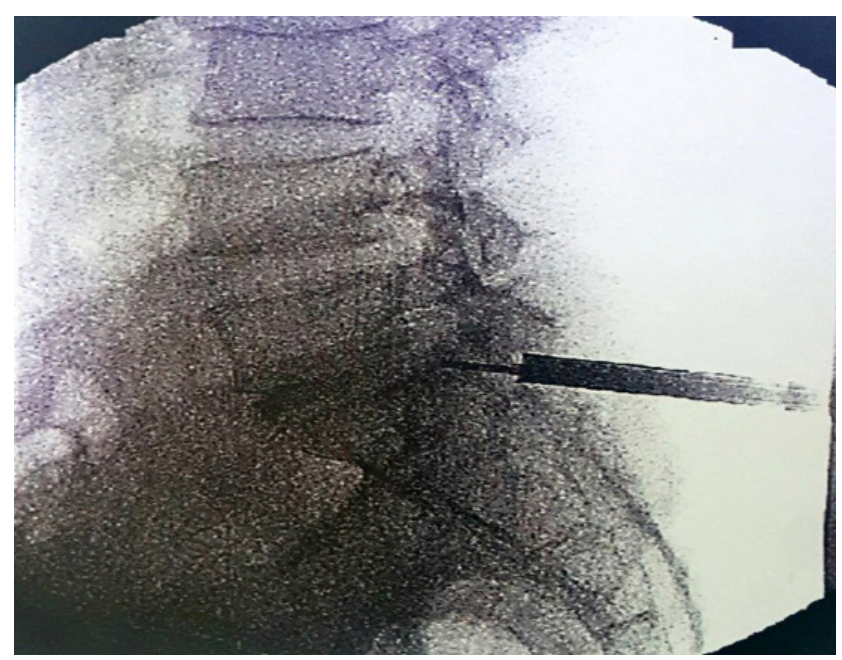

Fig. 8. C-arm positioning of cannula.

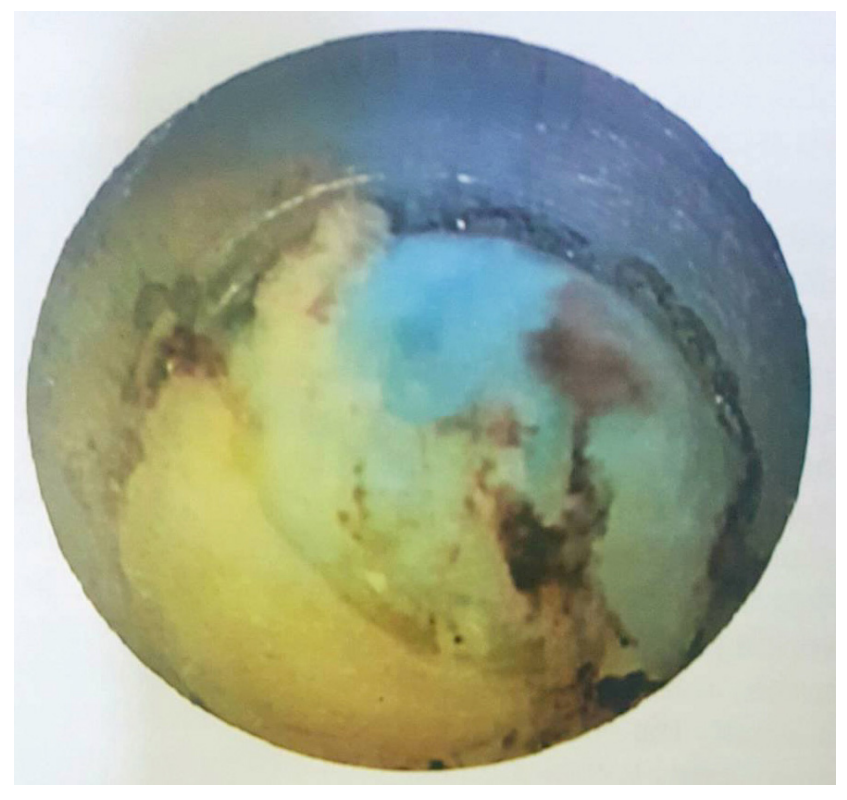

Fig. 10. Identification of Epidural fat and movements disc herniation.

remove fat and next structure which is seen is neural tissue. Working cannula is used to guard S1 root and herniation to be identified and removed with forceps (Fig. 10). Confirm a free movement of the nerve root (Fig. 11).

Recently endoscopic surgery for spinal canal stenosis is becoming more popular but it is not discussed here as it is not common in the adolescent patients.

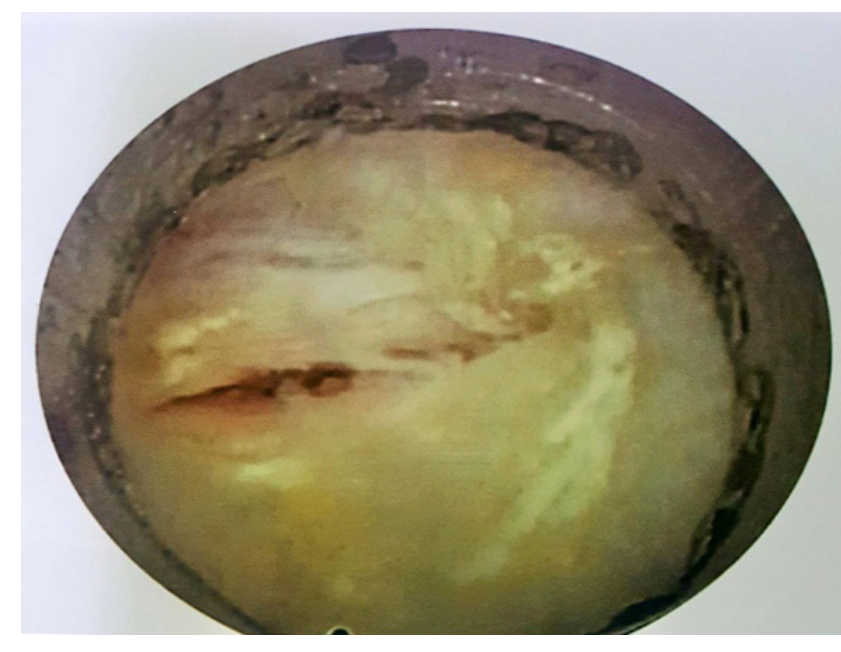

Fig. 9. Identification of two layers of the ligamentum flavum.

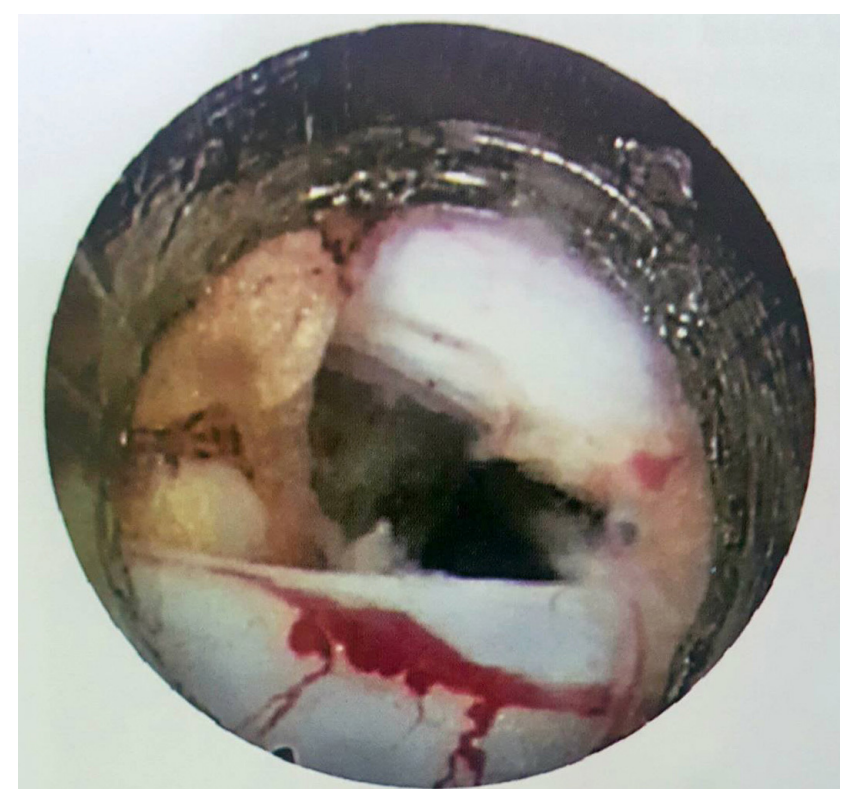

Fig. 11. End of decompression (free of the nerve roots).

\section{Complications}

- Immediate complications : 1) injury to the neural and vascular structures, 2) perforation of peritoneal sac and abdominal contents, 3) missed fragments, 4) exploration of wrong level or wrong side, and 5) instrument breakage - Early complications : 1) psoas hematoma, 2) postoperative hematoma formation, 3) cerebrospinal fluid cyst formation, and 4) infection

- Delayed complications : 1) recurrent disc herniation and 2) possible instability 


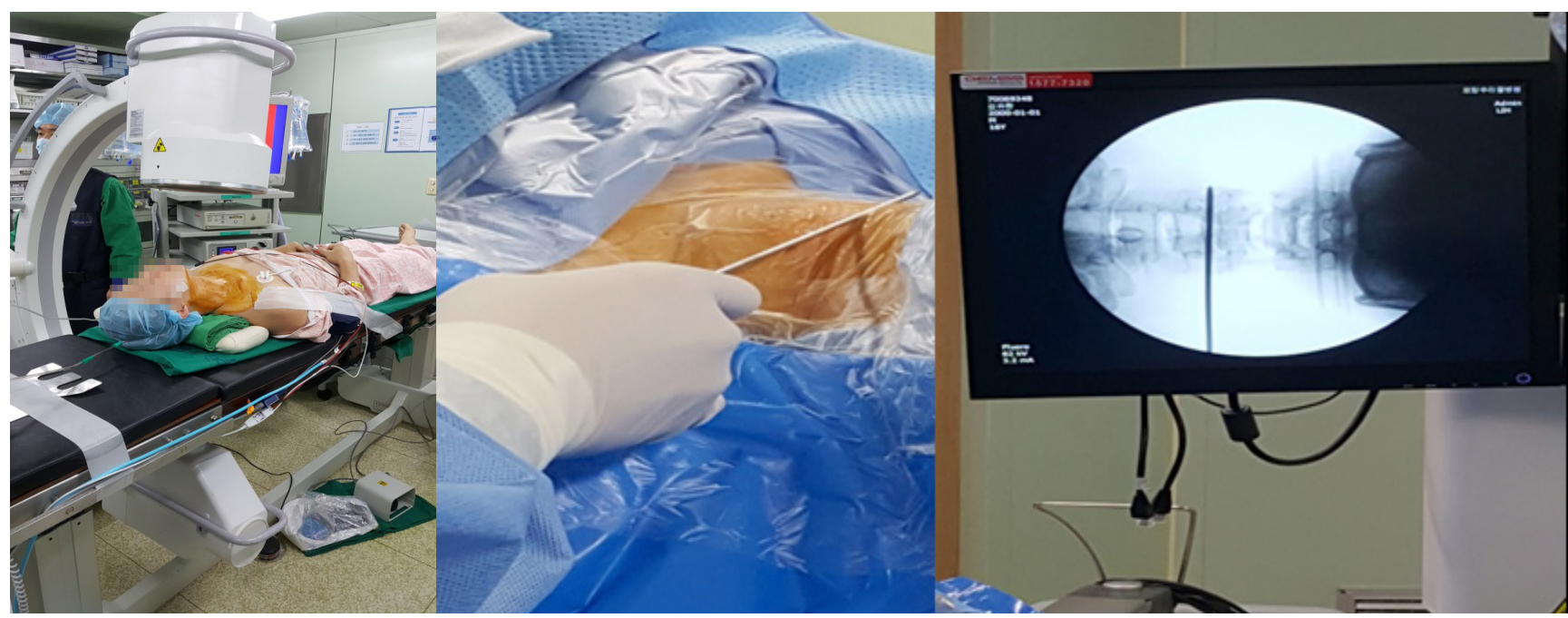

Fig. 12. Patient and C-arm positioning with level marking.

\section{ENDOSCOPIC CERVICAL SPINE SURGERY}

\section{Percutaneous endoscopic cervical discectomy (PECD)}

Advantage of doing anterior PECD is as it is performed as day care procedure under local anaesthesia so it avoid the fusion of that segment so the complications related to the fusion surgery can be reduced. Furthermore patient is awake so there is constant feedback from patient during procedure, so it is safer.

\section{Indications}

- Contained or non contained and central or paracentral disc herniation not responding to conservative treatment of appropriate duration with correlative MRI and CT images

- Annular tear with concordant pain on provocative discography

\section{Contraindications}

- Migrated disc herniation

- Calcified disc

- Collapse disc space $<5 \mathrm{~mm}$

- Instability

- Infection

- Past history of anterior cervical surgery

\section{Surgical approach}

- Patient is placed supine on radiolucent operating table with neck slightly extended by placing pillow between two

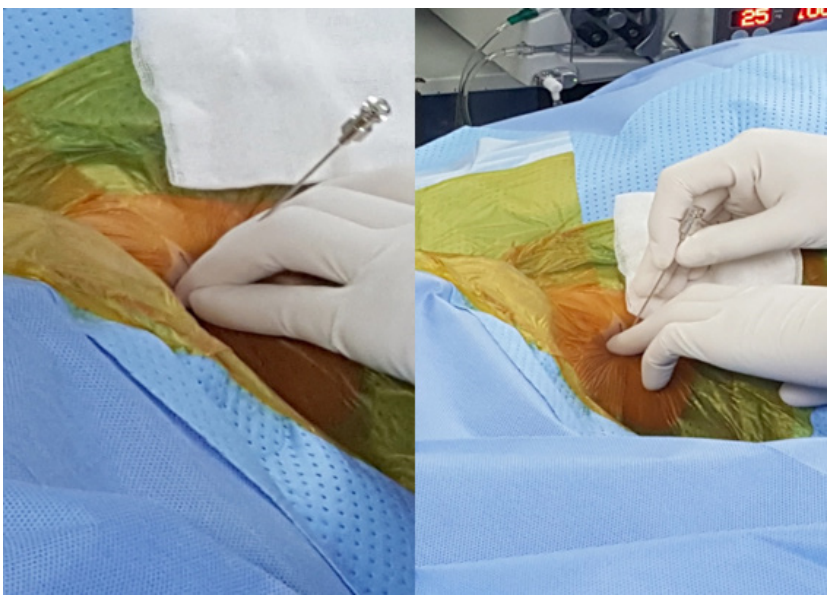

Fig. 13. Needle insertion.

shoulders and head is stabilised with adhesive tape, both shoulders are pulled down with adhesive tape to visualise lower cervical spine under C-arm. Level is marked under $\mathrm{C}$-arm and operative field prepared and draped (Fig. 12).

- Approach is usually opposite site of the herniation for paracentral and foraminal disc herniation and for central disc herniation right side for right handed surgeon and vice versa. Infiltrate the skin with $1 \%$ lidocaine along with conscious sedation given preoperatively (Intravenous Midazolam $0.05 \mathrm{mg} / \mathrm{kg}$ and $0.8 \mathrm{mg} / \mathrm{kg}$ Fentanyl and can be repeated if required).

- Palpate the carotid pulse with left hand. Trachea-oesophageal complex is pushed away by finger nails and feel anterior vertebral surface. So the safe interval is created by fingers of left hand and confirmed under C-arm. 
- Under fluoroscopy guidance insert 18 gauge needle through skin from the safe interval and advance till anterior disc surface, insert a needle from the centre of the disc between two longus colli to prevent injury to the cervical

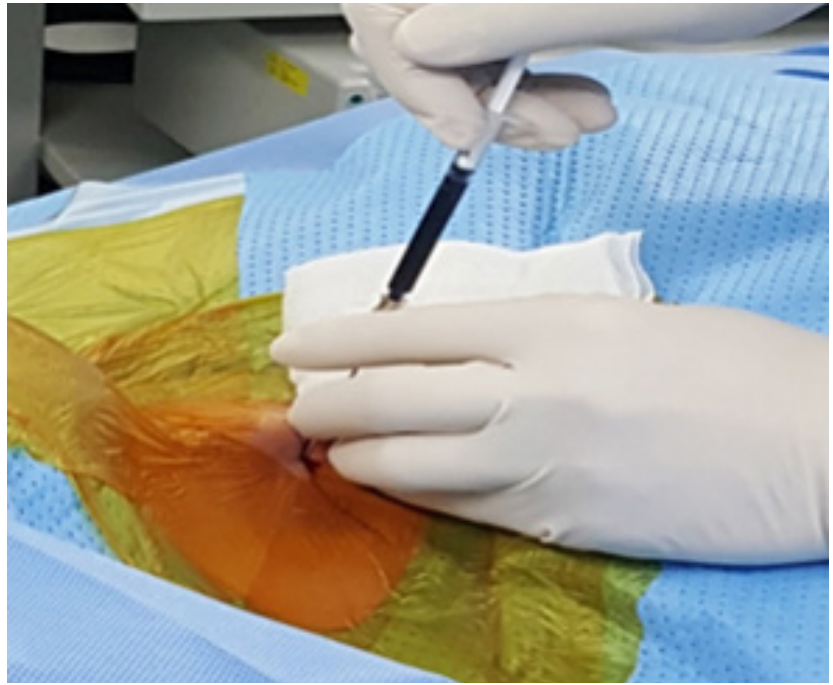

Fig. 14. Discography.

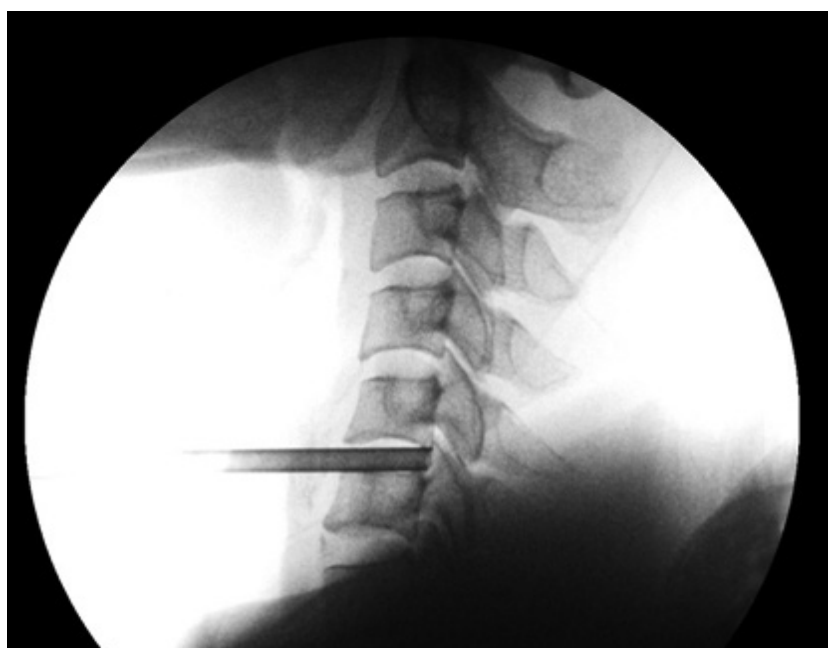

Fig. 15. Final position of cannula.

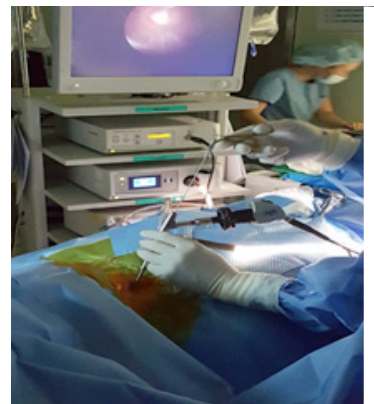

Fig. 16. Endoscope insertion. sympathetic chain and bleeding (Fig. 13).

- Perform a discography with $0.5 \mathrm{~mL}$ admixture of radio opaque dye, normal saline and indigo carmine in the ratio of $2: 2: 1$, it help to identify herniated fragment as its stains acidic degenerated nucleus pulposus to blue (Fig. 14).

- Exchange needle with guide wire, make skin incision of around $5 \mathrm{~mm}$ and introduce series of dilators. Finally replace it with appropriate size working cannula.

- Tip of cannula should be at posterior vertebral line in lateral view and according to the location of herniation in AP C-arm view (Fig. 15).

- Introduce the cervical endoscope (Spine Doctors) and remove herniated disc fragments (Fig. 16). If fragments are caught inside annulus use side firing Ho : YAG laser to make circular annular window to access the fragment (Fig. 17).

- Pulsating dura and posterior annulus is a sign of complete removal of fragments. Remove endoscope and cannula, close incision with single stitch (Fig. 18).
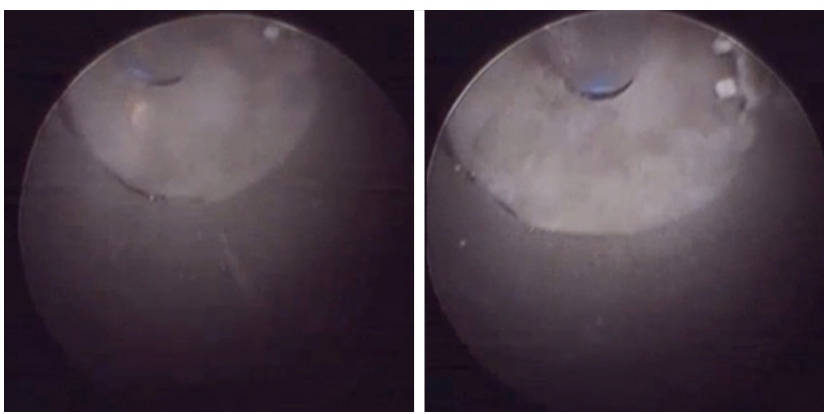

Fig. 17. Use of $\mathrm{Ho}$ : YAG laser to make annular window.

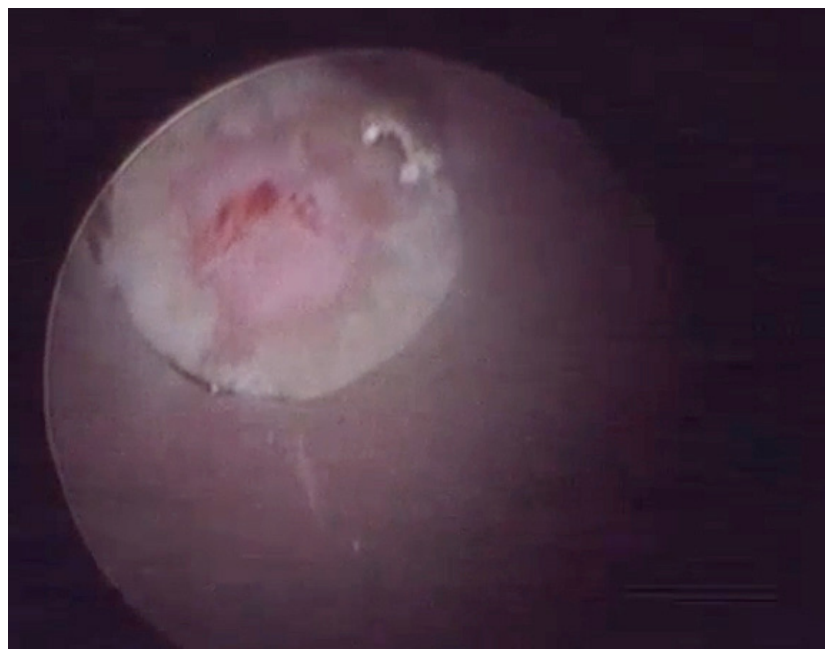

Fig. 18. End of decompression. 


\section{Percutaneous endoscopic posterior cervical fo- raminotomy}

Posterior cervical foraminotomy is another endoscopic procedure to deal with foraminal disc herniation which sometimes is difficult to deal with PECD and have advantage of its being without damaging anterior normal disc, the herniated foraminal fragment can be removed and there is obvious ad-

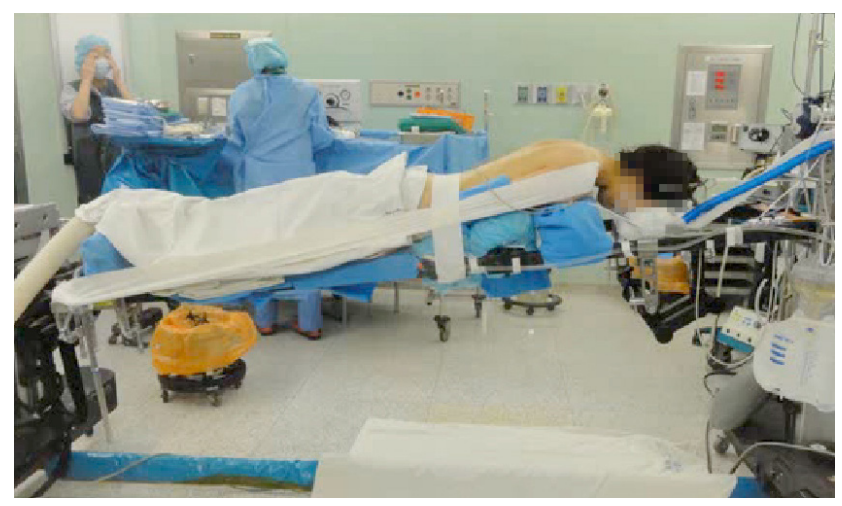

Fig. 19. Patient positioning.

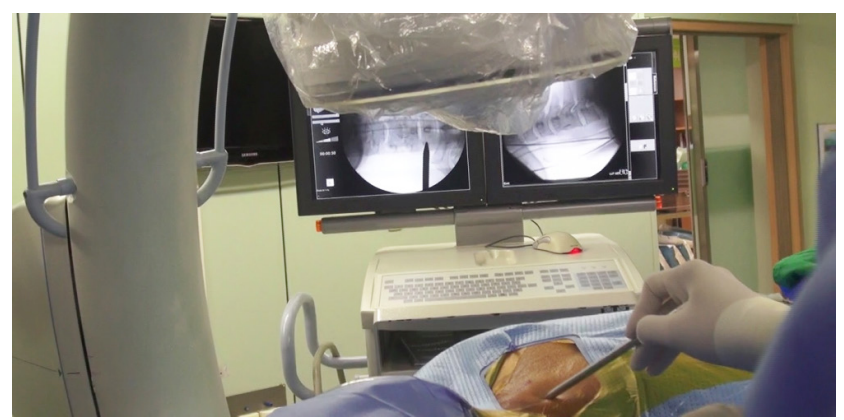

Fig. 20. Level marking.

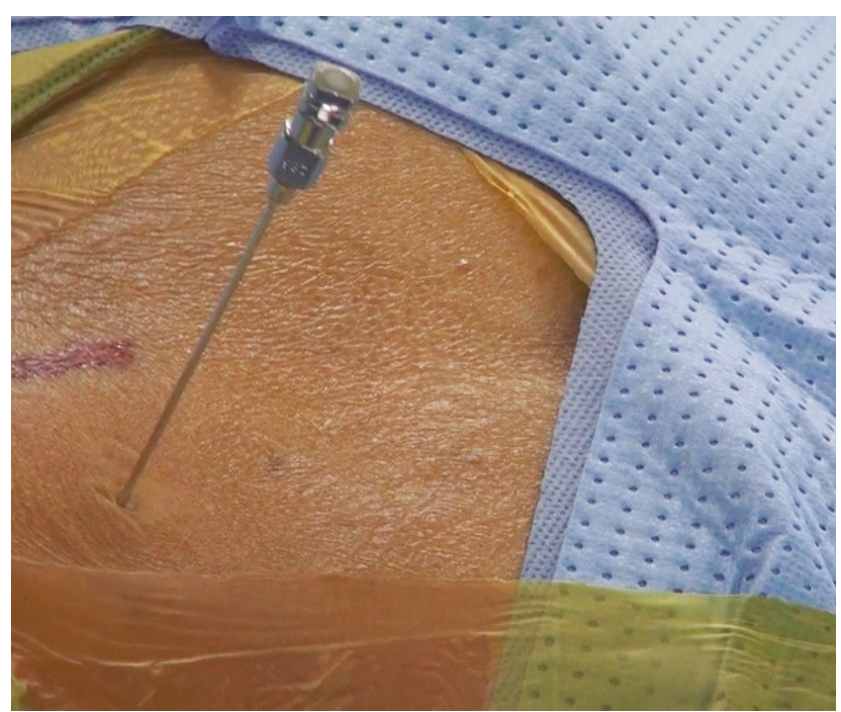

Fig. 21. Needle insertion. vantage of avoiding anterior cervical discectomy and fusion. It also called "key hole foraminotomy". It can be utilized for osteophytic foraminal stenosis.

\section{Indications}

- Foraminal disc herniations (predominantly unilateral arm pain)

- Single or multilevel foraminal stenosis (unilateral arm pain)

- persistent symptoms despite previous anterior cervical discectomy and fusion

\section{Contraindications}

- Axial neck pain

- Instability

- Presence of cervical kyphosis

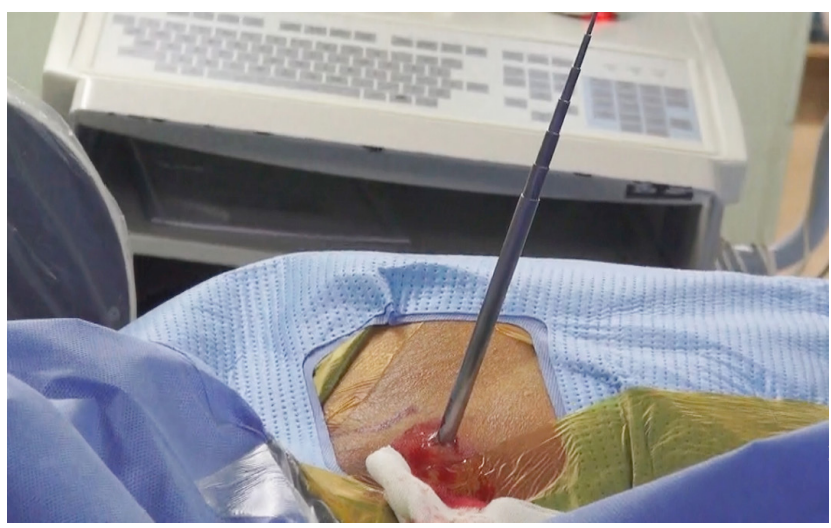

Fig. 22. Passage of serial dilators.

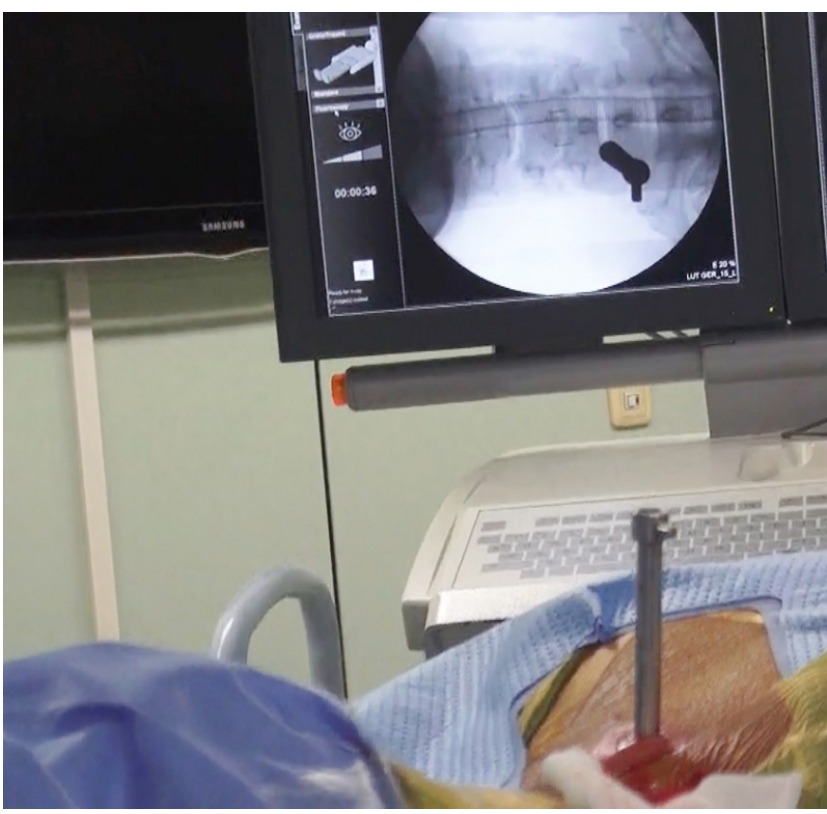

Fig. 23. Final positioning of cannula. 


\section{Surgical steps}

- Under general anaesthesia, patient is placed in prone and reverse trendelenburg's position (Fig. 19)

- Under fluoroscopy, facet joint is identified and needle is introduced (Fig. 20), followed by guide wire and sequential dilators (Fig. 21) and finally replaced with working cannula $(6.5 \mathrm{~mm})$ (Fig. 22). Introduce the endoscope (Spine Doctors) and visualise facet junction ('V' shaped area) (Fig. 23).

- Further procedure requires drilling of facet with burr and kerrison punches but there should be less than $50 \%$ of facet joint drilling (Figs. 24-26). Visualise the axilla and remove herniated fragment.

- Close the wound with single stitch.

\section{Complications of cervical endoscopy}

- Neurological injury like damage to the cervical cord or nerve root due to inadvertent use of forceps or laser (transient with laser).

- Vascular injury like carotid vessels during PECD and vertebral artery while foraminotomy.

- Visceral injury mainly oesophagus because it is soft collapsible tube and highly prone to injury while needle insertion in PECD.

\section{Percutaneous endoscopic thoracic discectomy}

Thoracic disc herniations (TDH) are less frequent than cer-

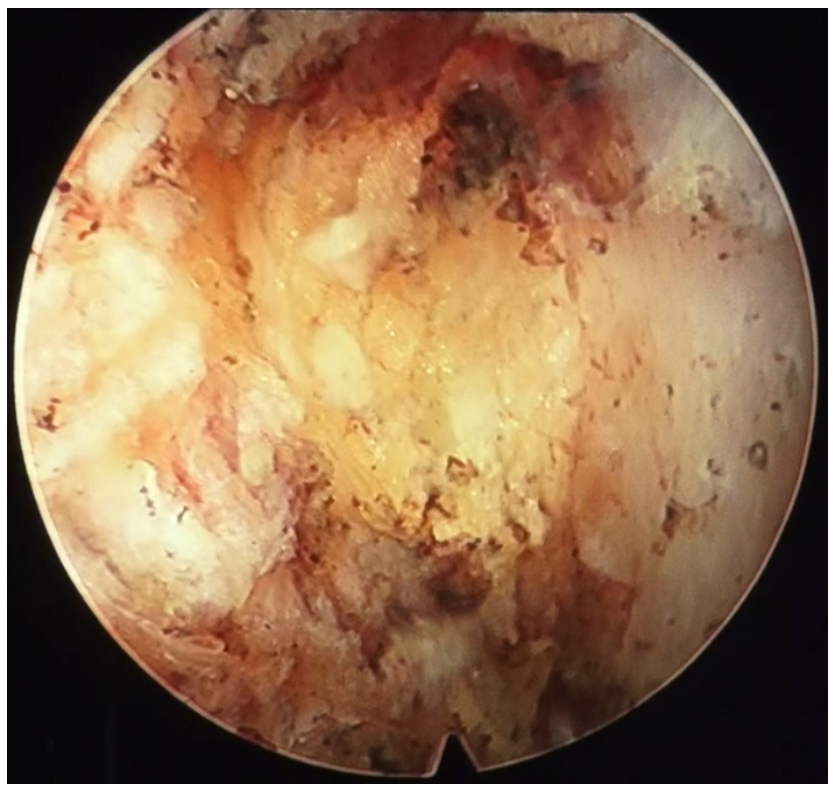

Fig. 24. Endoscopic view of facet ('V' shape area). vical or lumbar disc herniations, accounting for only 0.25 $0.75 \%$ of all disc herniations. Surgical treatment for TDH is thus very rare, constituting only $0.15-1.8 \%$ of all surgically treated disc herniations. With increasing use of MRI and CT, the prevalence of TDH is also increasing nowadays. PETD has been developed to reduce trauma and enhance the postoperative outcome for thoracic disc herniations from posterior or posterolateral approach. In 1997, Jho described the technique of Percutaneous endoscopic transpedicular thoracic discectomy from the posterolateral approach ${ }^{8)}$. This avoided the need

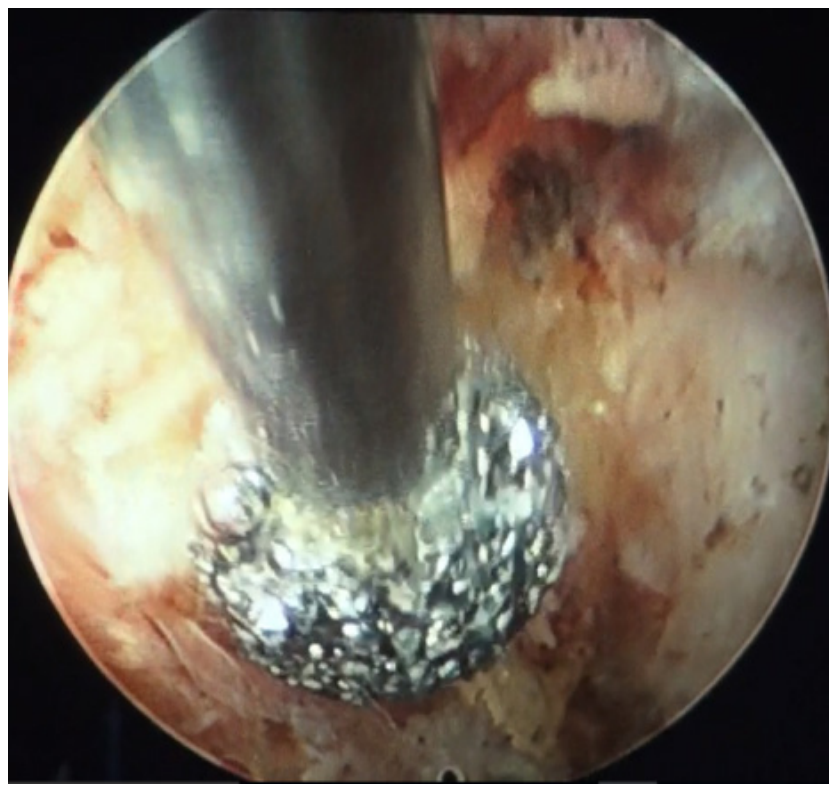

Fig. 25. Use of burr and kerrison punch for decompression.

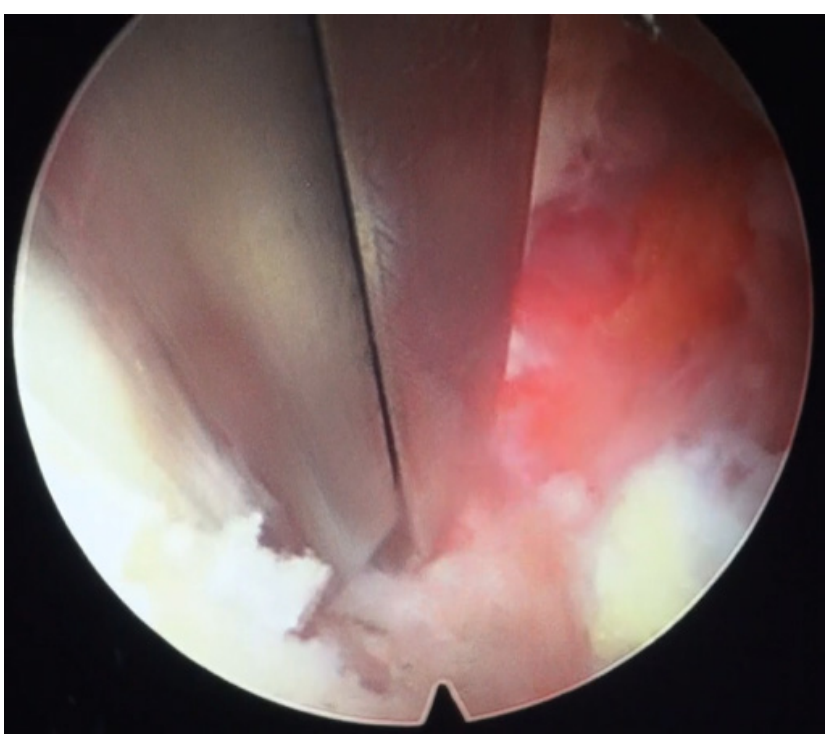

Fig. 26. Use of burr and kerrison punch for decompression. 


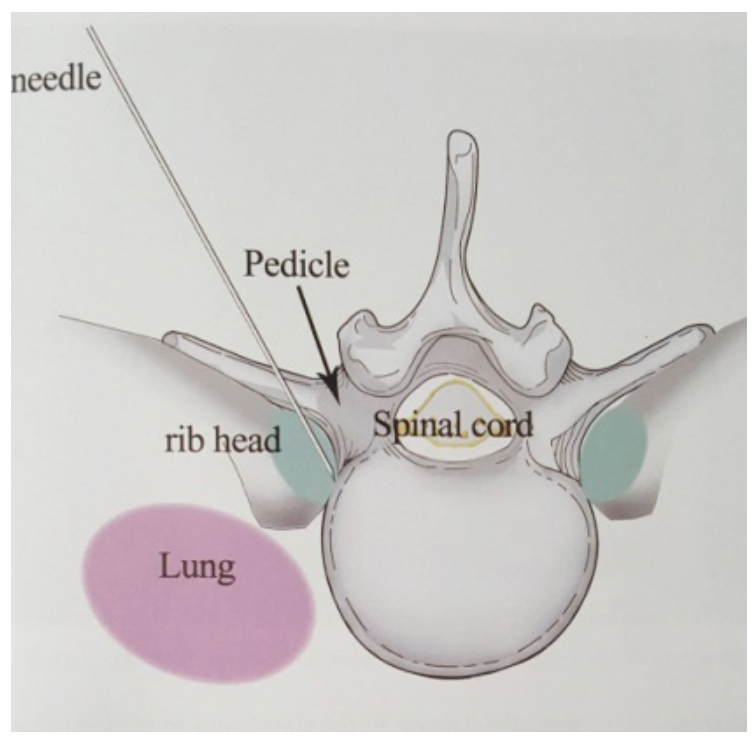

Fig. 27. Showing endoscopic approach to the thoracic spine.

for separate skin incisions in the chest wall for postoperative chest drainage as were used in thoracoscopic approaches. Later in 2010, Choi et al. ${ }^{2)}$ demonstrated the safety and efficacy of PETD from posterolateral approach by application of a low energy nonablative laser for thermodiscoplasty using a $4 \mathrm{~mm}$ 0-degree endoscope (Fig. 27). Currently, PETD has been described as a safe procedure with better outcomes than the conventional procedure for thoracic disc herniations.

\section{Indications}

- Soft thoracic disc herniation

- Axial back pain and/or radicular pain including the following

- Interscapular pain

- Thoracolumbar pain

- Anterior radiating chest pain

- Intercostal pain or low back pain

- Mild degree of myelopathy due to soft disc herniation without calcification

- Failure of adequate conservative therapy

\section{Contraindications}

- Hard or calcified disc

- Thoracic ossification of the posterior longitudinal ligament

- Evidence of acute or progressive degenerative spinal cord disease

- Severe disc narrowing

- Severe cord compression

\section{Complications}

- Neurological injury like damage to the spinal cord and its nerve roots

- Vascular injury like damage to the inferior vena cava or thoracic aorta can be life threatening

- Visceral injury like damage to the lung or mediastinal viscera

\section{References}

1. Choi G, Lee SH, Raiturker PP, Lee S, Chae YS : Percutaneous endoscopic interlaminar discectomy for intracanalicular disc herniations at L5-S1 using a rigid working channel endoscope. Neurosurgery 58(1 Suppl) : ONS59-ONS68; discussion ONS59-ONS68, 2006

2. Choi KY, Eun SS, Lee SH, Lee HY : Percutaneous endoscopic thoracic discectomy; transforaminal approach. Minim Invasive Neurosurg 53 : 25-28, 2010

3. Destandau $\mathrm{J}$ : A special device for endoscopic surgery of lumbar disc herniation. Neurol Res 21 : 39-42, 1999

4. Friedman WA : Percutaneous discectomy: an alternative to chemonucleolysis. J Neurosurg $13:$ 542-7, 1983

5. Gore SR, Yeung AT : Identifying sources of discogenic pain. Jour Minimally Invasive Spinal Technique 3 : 21-24, 2003

6. Hijikata S, Yamagishi M, Nakayama T, Oomori K : Percutaneous diskectomy: a new treatment method for lumbar disc herniation. J Toden Hosp 5 : 5-13, 1975

7. Hoogland $\mathrm{T}$ : Transforaminal endoscopic discectomy with foraminoplasty for lumbar disc herniation. Surg Tech Orthop Traumatol 40 : 55120, 2003

8. Jho HD : Endoscopic transpedicular thoracic discectomy. J Neurosurg 91(2 Suppl) : 151-156, 1999

9. Kambin P : Arthroscopic microdiscectomy. Arthroscopy 8 : 287-295, 1992

10. Kambin P : Arthroscopic microdiscectomy in Kambin PR (ed) : Minimal Intervention in Spinal Surgery. Baltimore : Urban \& Schwarzenberg, 1991, pp67-1100

11. Kambin P : Endoscopic laser discectomy. FDA, IDE G890238-S1, 1990

12. Kambin $P$ : History of Surgical management of herniated lumbar discs from cauterization to arthroscopic and endoscopic spinal surgery in Kambin P (ed) : Arthroscopic and Endoscopic Spinal Surgery, ed 2. Totowa : Humana Press Inc., 2005, pp1-27

13. Kambin P, Gellman $H$ : Percutaneous lateral discectomy of the lumbar spine: a preliminary report. Clin Orthop 174 : 127-132, 1983

14. Kambin P, Sampson S: Posterolateral percutaneous suction-excision of herniated lumbar intervertebral discs. Report of interim results. Clin Orthop (207) : 37-43, 1986

15. Kim DH, Choi G, Lee $S H$ : Endoscopic spine proceduresed. New 
York : Thieme, 2011, pp42-58

16. Mathews HH : Transforaminal endoscopic microdiscectomy. Neurosurg Clin North Am 7 : 59-63, 1996

17. Mirkovic SR, Schwartz DG, Glazier KD : Anatomic considerations in posterolateral procedures. Spine (Phila Pa 1976) 20 : 1965-1971, 1995

18. Onik G, Helms CA, Ginsburg L, Hoaglund FT, Morris I : Percutaneous lumbar discectomy using new aspiration probe. AJR Am J Roentgenol 144 : 1137-1140, 1985

19. Ruetten $\mathrm{S}$, Komp M, Godolias $\mathrm{G}$ : An extreme lateral access for the surgery of lumbar disc herniations inside the spinal canal using the fullendoscopic uniportal transforaminal approach-technique and prospec- tive results of 463 patients. Spine (Phila Pa 1976) $30: 2570-2578$, 2005

20. Smith MM, Foley KT : Microendoscopic discectomy(MED): the first 100 cases. Neurosurgery $43:$ 702, 1998

21. Yeung AT : The evolution and advancement of endoscopic foraminal surgery: one surgeon's experience incorporating adjunctive techologies. SAS J 1 : 108-117, 2007

22. Yeung AT, Gore SR : Evolving methodology in treating discogenic back pain by Selective Endoscopic Discectomy (SED) and thermal annuloplasty. J Minimally Invasive Spinal Tech 1 : 8-16, 2001 